Brain (1994), 117, 1271-1282

\title{
A graded task approach to the functional mapping of brain areas implicated in auditory-verbal memory
}

\author{
P. M. Grasby, ${ }^{1,2}$ C. D. Frith, ${ }^{1,3}$ K. J. Friston, ${ }^{1}$ J. Simpson, ${ }^{1}$ P. C. Fletcher, ${ }^{1,2}$ R. S. J. Frackowiak ${ }^{1,4}$ \\ and R. J. Dolan ${ }^{1,2,4}$
}

${ }^{1} M R C$ Cyclotron Unit, Hammersmith Hospital, ${ }^{2}$ Royal Free Hospital School of Medicine, ${ }^{3}$ Psychology Department, University College London and ${ }^{4}$ National Hospital for Neurology and Neurosurgery, London, UK

Correspondence to: P. M. Grasby, MRC Cyclotron Unit, Hammersmith Hospital, London W12 OHS, UK

\begin{abstract}
Summary
Positron emission tomography measurements of regional cerebral blood flow ( $r C B F$ ) were performed in normal volunteers during a graded auditory-verbal memory task. Subjects were required to remember and then immediately, and freely, recall a series of auditorily presented word lists varying from two to 13 words in length. Significant regional correlations between $\mathrm{rCBF}$ and memory load (word list length) were identified using statistical parametric mapping. Increasing memory load correlated with increasing $r C B F$ in the cerebellar vermis and hemispheres, thalamus bilaterally, the superior and middle frontal gyri bilaterally, anterior insular regions bilaterally, anterior cingulate, precuneus and
\end{abstract}

Key words: memory; PET; auditory-verbal; brain mapping left and right lateral premotor areas. Increasing memory load also correlated with decreasing $r C B F$ in the left and right superior temporal/insular regions, medial frontal gyrus, Brodmann's area 37 bilaterally, cuneus, inferior parietal lobule bilaterally and the mid-portion of the cingulate cortex. The pattern of $r C B F$ change closely resembled that identified in a previously reported study using a cognitive subtraction paradigm and provides further evidence for a widespread neural system subserving auditory-verbal memory. The patterns of $r C B F$ response suggest that the areas identified are associated with limited capacity processes for encoding and retrieval.

\section{Introduction}

Brain areas implicated in auditory-verbal memory have traditionally been identified on the basis of neuropsychological studies in select patient populations with demonstrable brain pathology. Neuropsychological studies of amnesic patients, with localized brain damage, in particular, have had a predominant role in establishing the neural correlates of memory function. However, the difficulty of this 'lesion model' lies in relating memory function to the integrated functional anatomy of the intact living brain (Damasio and Geschwind, 1985). Functional brain-imaging techniques, using PET measurements of regional cerebral blood flow $(\mathrm{rCBF})$ or glucose utilization, now provide a complementary approach to the 'lesion model' in determining the anatomical basis of higher mental functions (Raichle, 1987; Frith et al., 1991a). Positron emission tomography has recently been applied to the in vivo study of human memory function in both normal volunteers (Roland and Seitz, 1989; Squire et al., 1992; Grasby et al., 1993a,b; Jonides et al., 1993; Paulesu et al., 1993; Petrides et al., 1993) and patients with specific mnemonic deficits (Fazio et al., 1992, Perani et al., 1993).

Using a PET activation paradigm involving the immediate free recall of subspan (i.e. five words) and supraspan (i.e. 15 words) word lists we have identified the neuroanatomical components of an auditory-verbal memory system using the 'cognitive subtraction' technique (Fox and Mintun, 1989; Grasby et al., 1993a). An important assumption in cognitive subtraction is that the profile of $\mathrm{rCBF}$ difference between two sets of PET scans (in each of which subjects perform diffetent psychological tasks) isolates the neural correlates of the essential difference, in terms of cognitive components, between tasks. This method has its origins in the work of Donders who used reaction time measurements to study successive stages of psychological processing (Sternberg, 1969). The validity of cognitive subtraction thus rests on theoretical assumptions about the componential nature of the psychological processes underlying a particular task. An alternative approach that rests on fewer assumptions about 
the componential nature of the psychological processes is that of a graded response paradigm. Here a parameter of psychological interest is systematically varied across PET scans (e.g. Price et al., 1992) and correlations are obtained between rCBF responses and the parameter manipulated. Such an approach identifies brain systems that respond over a range, or above a threshold, of the manipulated variable. In this paper we describe an experiment that extends our previous work by using a graded memory task to map the brain systems subserving auditory-verbal memory.

\section{Methods \\ Subjects}

Ten right-handed volunteers undertook the study (nine males, one female). Subjects were aged from 21 to 40 years. All subjects were physically fit and gave written informed consent obtained in accordance with the declaration of Helsinki. The study was approved by the local hospital ethics committee and permission to administer radioactivity was obtained from the Advisory Committee on Radioactive Substances (ARSAC) UK.

\section{Positron emission tomography scanning}

Each subject underwent 12 serial rCBF measurements (emission scans) over a $3 \mathrm{~h}$ period with a CTI model 953BPET scanner (CTI Inc., Knoxville, Tenn., USA). Collimating septa were retracted which allowed for a considerable increase in the sensitivity of the PET camera and the number of recorded useful counts from the administered radiation (Townsend et al., 1991; Bailey et al., 1991a). The radiolabelled tracer used was $\mathrm{H}_{2}{ }^{15} \mathrm{O}$ given as an infusion over $120 \mathrm{~s}$ followed by a $30 \mathrm{~s}$ flush of saline. The total amount of tracer injected per subject was $135 \mathrm{mCi}$ with a calculated whole body-effective dosimetry of $5 \mathrm{mSv}$. A transmission scan of 20 min duration was obtained prior to the administration of tracer and was used to correct emisssion scans for attenuation effects. For each PET measurement of the distribution of radioactivity, a scan lasting $165 \mathrm{~s}$ was acquired. The integrated radioactive counts accumulated over this period were used as an index of rCBF (Mazziotta et al., 1985; Fox and Mintun, 1989). The emission scans began $30 \mathrm{~s}$ after the start of infusion of radiolabelled tracer. This time coincided with the arrival of radioactivity in the head as measured by the total count rate recorded by the scanner. The count rate rose monotonically over at least $120 \mathrm{~s}$ of the $165 \mathrm{~s}$ emission scan. All auditory-verbal memory tasks commenced $10 \mathrm{~s}$ before the emission scan and lasted for its duration.

\section{Graded auditory-verbal memory tasks}

During scanning six subjects were asked to remember and to freely recall, immediately, a series of auditorially presented word lists from two to 13 words in length (Table 1). Words were high frequency, concrete, imageable (e.g. dress, water, artist) and were taken from the Oxford Psycholinguistic Database (Quinlan, 1992). A total of 60-66 different words were presented during each scan. Words were spoken by the experimenter at the rate of one every $2 \mathrm{~s}$. Word list length was kept constant for each scan but was randomized amongst scans and subjects. Word list length, and therefore the load placed on auditory-verbal memory systems, was thus varied systematically across the 12 scans. Subjects responded freely without pacing. Words correctly recalled were recorded for each word list presentation. Subject's eyes were closed during scanning.

\section{Control tasks}

In the graded response paradigm the pattern of auditory stimulation and speech output varied systematically with increasing word list length, although the number of words presented in total was similar for all scans (60-66 words). Thus, in the two word list memory task, auditory stimulation occurred for $2 \mathrm{~s}$ followed by speech output, whilst in the 13 word list task auditory stimulation was for $24 \mathrm{~s}$ followed by speech output. Likewise the time period for speech output varied systematically across scans. To examine the influence that the patterning of intermittent auditory stimulation and speech output had on rCBF, four further subjects received similar tasks but without an increasing memory load (Table 1). This was achieved by using 2-13 word lists in which a single word was repeatedly presented and was then repeated the requisite number of times by the subject. After the correct number of repetitions (signalled by the experimenter begining the word list) the word list was presented again. Different single words were used in different scans and subjects responded freely without pacing.

Table 1 Design of memory and control tasks

\begin{tabular}{|c|c|c|}
\hline & Auditory input & Speech output \\
\hline \multicolumn{3}{|l|}{ Memory task } \\
\hline Two word list & 'Dog, water' & 'Dog, water' \\
\hline $\begin{array}{l}\text { Three word list } \\
\text { Etc. }\end{array}$ & 'Wine, car, bottle' & 'Car, bottle, wine' \\
\hline \multicolumn{3}{|l|}{ Control task } \\
\hline Two word list & 'Cat, cat' & 'Cat, cat' \\
\hline $\begin{array}{l}\text { Three word list } \\
\text { Etc. }\end{array}$ & 'Pot, pot, pot' & 'Pot, pot, pot' \\
\hline
\end{tabular}

In the above examples 30 two word lists are presented (total number of words presented during scan $=60$ ), 20 three word lists are presented (total number of words presented during scan $=60$ ), etc. In the memory tasks, each two word list consists of different words, each three word list consists of different words, etc. In control tasks, every two word list consists of the same word, every three word list consists of the same word, etc. 


\section{Image analysis and statistical parametric mapping (SPM)}

Images were examined in ANALYZE (BRU, Mayo Foundation, Rochester, Minn., USA; Robb, 1990). Statistical analysis was performed in PROMATLAB (MathWorks Inc., Natick, Mass., USA) using statistical parametric mapping (SPM) (MRC Cyclotron Unit, Hammersmith Hospital, London, UK).

\section{Anatomical normalization of scans}

To correct for head movement between scans, all images from each subject were aligned using Automated Image Reconstruction (AIR) software (Woods et al., 1992). Following realignment images were then stereotactically normalized (Friston et al., 1989, 1991a). Stereotactic normalization of PET images allows comparison of scan data in identical pixels across different subjects and scans. During normalization a Gaussian filter of $20 \times 20 \times 12 \mathrm{~mm}$ (full width half maximum in the $x, y$ and $z$ planes, respectively) was used to remove high-frequency noise in the images and to accommodate differences in gyral functional anatomy between subjects.

\section{Removal of confounding effect of global activity} within and between subjects

Following stereotactic normalization, as described above, all scans (memory and control groups separately) were subject to an analysis of covariance (ANCOVA) (Wildt and Ahtola, 1978). This procedure removes the confounding effect of differences in global activity across scans and normalizes global activity (radioactive counts) to a notional mean rCBF of $50 \mathrm{ml} / \mathrm{dl} / \mathrm{min}$ (Friston et al., 1990). For each pixel, the ANCOVA generated 12 condition specific mean rCBF values and associated error variances.

\section{Statistical analysis and creation of SPMS}

Two methods of statistical analysis were used to examine the data set generated by the ANCOVA. One method used appropriately weighted linear contrasts (Hand and Taylor, 1987) to derive a $t$ statistic for assessment of the correlation of $\mathrm{rCBF}$ with word list length. The second method used a prinicipal components analysis (PCA) (see below). The former technique is essentially hypothesis led, whilst the latter is data led. With the first method the set of pixel $t$ values constitutes a SPM indicating areas of significant change of brain activity in association with the contrasts specified (Friston et al., 1991 b). Linear contrasts are weightings applied to each of the 12 condition mean rCBF values, for each pixel. Word list length was chosen for the linear contrasts rather than memory performance, as word list length was taken to represent the theoretical load placed on memory systems in the brain. With so many pixels examined, many $t$ values can reach conventional levels of significance by chance. Therefore the location of all pixels with a $t$ value corresponding to $P<0.001$ was used to define the profile of rCBF correlations with word list length. This level of significance has been found to protect adequately against false positives (Bailey et al., 1991b). Comparisons were also made with a group of four subjects studied under the control condition of word list repetition but without increasing memory load (i.e. two to 13 word list length but with a single word per list). For this comparison, weighted contrasts were used to define correlations between rCBF and word list length that were significantly greater for the memory load group than the non-memory load controls (the ANCOVA for each group being computed separately). For this comparison, the threshold of $P<0.001$ was also used.

A recursive principal components technique developed for the analysis of PET data sets (Friston et al., 1993) was also used in addition to the correlation analysis described above. The method is essentially a data-led approach which allows determination of the important features in a correlation matrix in terms of principal components or eigenvectors. The correlation matrix in this case being the data set of $\mathrm{rCBF}$ values in all brain pixels across the 12 scans. Each eigenvector is the linear combination that accounts for independent amounts of variance in the observed data set (Friston et al., 1993). The recursive PCA was undertaken on the ANCOVA adjusted mean rCBF values for the six subjects in the memory experiment.

\section{Results \\ Memory performance}

All subjects were able to perform the graded word list memory task. All six subjects achieved $100 \%$ correct recall of items from the two, three and four word list tasks but thereafter the percentage of words correctly recalled declined. The total number of words correctly recalled tended to be constant from the seven or eight word list tasks and above (Table 2).

Table 2 Group memory performance

\begin{tabular}{lll}
\hline List length & Percent correct recall & Group \\
\hline 2 & 100 & 2.0 \\
3 & 100 & 3.0 \\
4 & 100 & 4.0 \\
5 & 96 & 4.8 \\
6 & 93 & 5.6 \\
7 & 89 & 6.2 \\
8 & 85 & 6.8 \\
9 & 77 & 6.9 \\
10 & 71 & 7.1 \\
11 & 70 & 7.7 \\
12 & 59 & 7.1 \\
13 & 62 & 8.0 \\
\hline
\end{tabular}




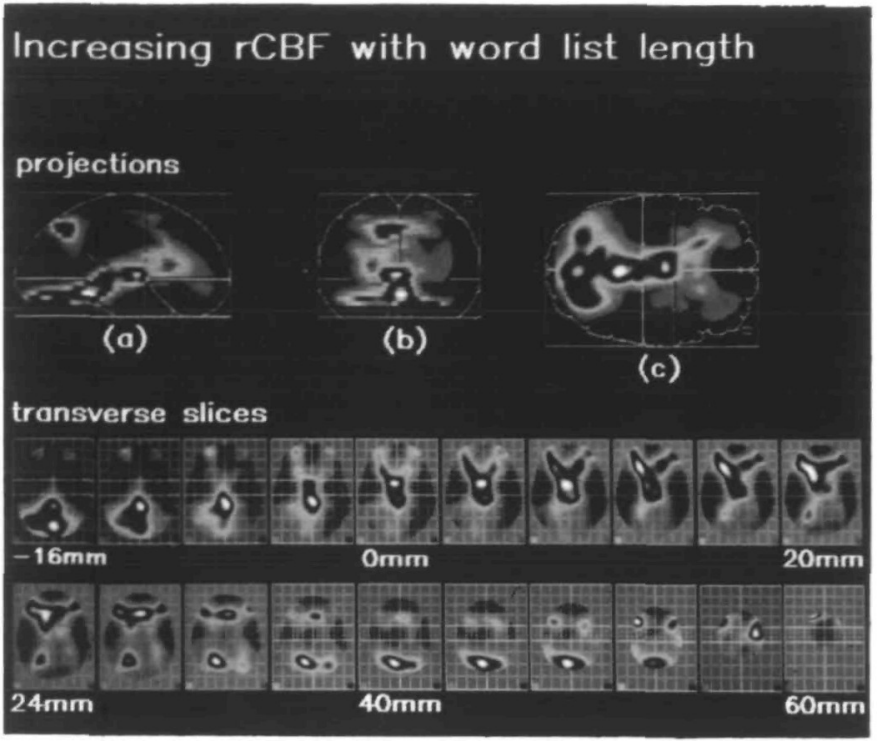

Fig. 1 Location of positive correlations of rCBF with word list length. Upper images are of the spatial distribution of significant pixels at $P<0.001$ shown as integrated projections along sagittal (a), coronal (b) and transverse views (c) of the Tailarach and Tournoux brain atlas. $\mathrm{R}=$ right. Lower images are transverse slices of the statistical volume relative to the AC-PC line. Numbers (e.g. $40 \mathrm{~mm}$ ) refer to the level of the transverse slice in millimetres relative to the AC-PC line. Anterior is at the top of each slice. The subject's right is on the right. The superimposed grid provides the stereotactic coordinates from the atlas of Talairach and Tournoux (1988). The coloured square in the bottom left of each image plane indicates a statistical threshold of $Z=3.09, P<0.001$. Images are scaled to the image maximum for each plane. For comparison of the correlations for each area identifed refer to Table 3 .

\section{Positive correlations of $\mathrm{rCBF}$ with two to 13 word list length}

Increasing word list length correlated with increased blood flow in the cerebellar vermis, cerebellar hemispheres, left and right thalamus, the middle and superior frontal gyri of the left and right prefrontal cortex [BA 10 (lateral aspect), 46], right and left anterior insula regions, anterior cingulate (BA 32/24), precuneus (BA 7) and the left and right lateral premotor areas (BA 6) (Fig. 1 and Table 3).

\section{Negative correlations of $\mathrm{rCBF}$ with two to 13 word list length}

Increasing word list length correlated negatively with blood flow in the following areas: the medial frontal gyrus [BA 8, 9, 10 (medial aspect), 11], left inferior frontal gyrus (BA 47), left and right Brodmann's area 37 (at the junction of the middle temporal gyrus and middle occipital gyrus), left and right insular/superior temporal cortex, the cuneus (BA 18), left and right inferior parietal lobule (BA 39/40) and the midportion of the cingulate gyrus (BA 24) (Fig. 2 and Table 4).

\section{Comparison of control task with graded response memory task: positive and negative correlations}

When the pattern of positive correlations in the memory experiment was statistically compared with rCBF correlations produced in the control task (repetition of a single word with variable list length) all the foci of correlation remained

Table 3 Foci of positive correlation of word list length with $r C B F$

\begin{tabular}{|c|c|c|c|}
\hline Brain area & $\begin{array}{l}\text { Coordinates } \\
(x, y, z)\end{array}$ & $Z$ value & $\begin{array}{l}\text { Control } \\
\text { task }\end{array}$ \\
\hline Cerebellum (vermis) & $\begin{array}{l}2,-76,-16 \\
2,-42,-12\end{array}$ & $\begin{array}{l}10.2 \\
10.5\end{array}$ & ND \\
\hline Cerebellum (hemispheres) & $\begin{array}{r}-28,-72,-16 \\
24,-72,-20\end{array}$ & $\begin{array}{l}9.0 \\
9.6\end{array}$ & ND \\
\hline Superior/middle frontal gyrus (BA 10,46$)$ & $\begin{array}{rrr}-24, & 48, & -8 \\
30, & 48, & 4 \\
38, & 40, & 16\end{array}$ & $\begin{array}{l}6.0 \\
5.4 \\
6.0\end{array}$ & $\mathrm{D}$ \\
\hline Thalamus & $\begin{array}{rr}2,-28, & 4 \\
-2,-4, & 4\end{array}$ & $\begin{array}{r}9.1 \\
10.3\end{array}$ & ND \\
\hline Anterior insular & $\begin{array}{rrr}-22, & 22, & 12 \\
16, & 24, & 8\end{array}$ & $\begin{array}{l}8.5 \\
6.9\end{array}$ & ND \\
\hline Anterior cingulate (BA 32/24) & $0, \quad 20, \quad 28$ & 6.3 & ND \\
\hline Precuneus (BA 7) & $\begin{array}{ll}24,-64, & 36 \\
-8,-60, & 44\end{array}$ & $\begin{array}{l}5.7 \\
9.4\end{array}$ & ND \\
\hline Lateral premotor area (BA 6) & $\begin{array}{rrr}22, & 0, & 48 \\
-30, & 6, & 52\end{array}$ & $\begin{array}{l}5.2 \\
6.5\end{array}$ & ND \\
\hline
\end{tabular}

$\mathrm{ND}=$ positive correlation focus not detected in control task in region specified; $\mathrm{D}=$ positive correlation focus detected in control task in region specified; $Z$ values $=$ normalized $t$ statistic values from the SPM-the larger the $Z$ value the greater the statistical association between increasing rCBF and word list length. $Z=3.09=\mathrm{P}<0.001$. 


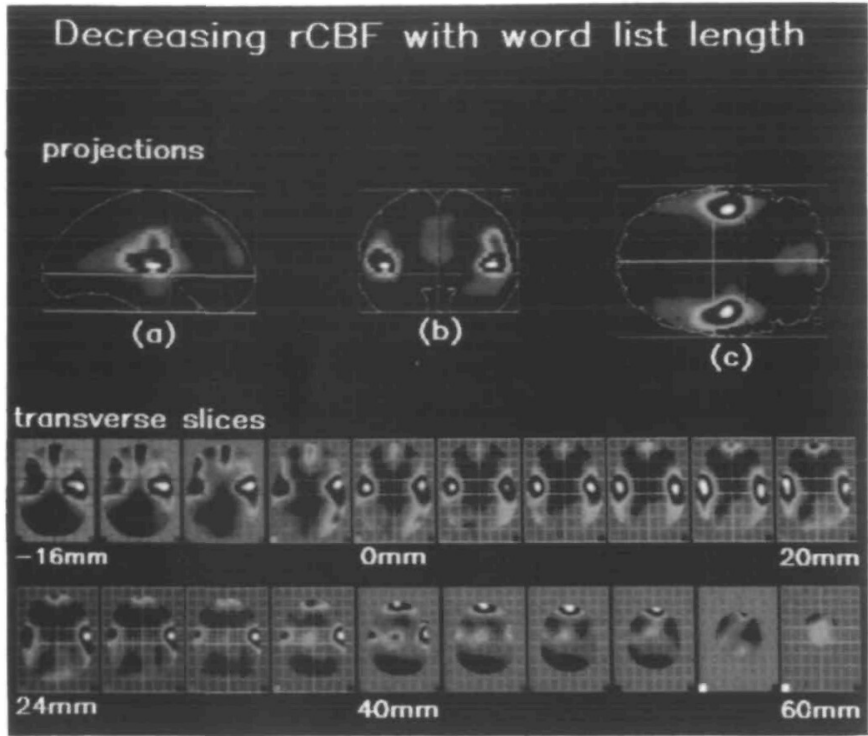

Fig. 2 Location of negative correlations of $\mathrm{rCBF}$ with word list length. Upper images are of the spatial distribution of significant pixels at $P<0.001$ shown as integrated projections along sagittal (a), coronal (b) and transverse views (c) of the Tailarach and Tournoux brain atlas. $\mathbf{R}=$ right. Lower images are transverse slices of the statistical volume relative to the AC-PC line. Numbers (e.g. $40 \mathrm{~mm}$ ) refer to the level of the transverse slice in millimetres relative to the AC-PC line. Anterior is at the top of each slice. The subjects right is on the right. The superimposed grid provides the stereotactic coordinates from the atlas of Talairach and Tournoux (1988). The coloured square in the bottom left of each image plane indicates a statistical threshold of $Z=3.09, P<0.001$. Images are scaled to the image maximum for each plane. For comparison of the correlations for each area identifed refer to Table 4 . significant, apart from correlations in the prefrontal cortex (Fig. 3). In other words, the prefrontal activations in the memory and control tasks produced similar correlations with rCBF. No significant negative correlations of $\mathrm{rCBF}$ with word list length were observed in the control task.

\section{Principal components analysis}

The principal components analysis identified three eigenvectors that accounted for $82 \%$ of the variance in the data set. The first eigenvector accounted for $67 \%$ of the variance and was weighted across the 12 scans (conditions) as shown in Fig. 4. The weighting of the first eigenvector across the 12 scans (conditions) correlated with subjects mean memory performance across the same scans (correlation coefficient 0.978) (Fig. 4).

\section{Pattern of $\mathrm{rCBF}$ response in select brain areas} In many brain areas the pattern of $\mathrm{rCBF}$ response to increasing word list length was for maximal rCBF change from lists of two to six or seven words in length with, in some areas, relatively small rCBF changes beyond this point (Fig. 5).

\section{Discussion \\ Brain areas activated in comparison with a cognitive subtraction paradigm}

The graded memory task identified the majority of the anatomical regions previously reported using a cognitive subtraction paradigm (Grasby et al., 1993a), including the

Table 4 Foci of negative correlation of word list length with $r C B F$

\begin{tabular}{lrcl}
\hline Brain area & $\begin{array}{l}\text { Coordinates } \\
(x, y, z)\end{array}$ & $Z$ value & $\begin{array}{l}\text { Control } \\
\text { task }\end{array}$ \\
\hline Inferior frontal gyrus (BA 47) & $-40,26,-12$ & 4.7 & ND \\
Medial frontal gyrus (BA 8, 9, 10,11) & $2,52,-12$ & 4.8 & ND \\
& $-4,54,20$ & 7.3 & \\
Brodmann's area 37 & $-2,38,44$ & 6.6 & ND \\
Superior temporal/insular cortex & $40,-64,44$ & 5.8 & \\
& $-46,-68,8$ & 5.7 & ND \\
Cuneus (BA 18) & $-42,-12,8$ & 12.4 & \\
& $42,-12,8$ & 12.4 & ND \\
& $-18,-80,20$ & 3.8 & \\
Inferior parietal lobule (BA 39/40) & $20,-74,20$ & 4.2 & \\
& $-2,-78,24$ & 4.0 & \\
Cingulate (BA 24) & $14,-74,24$ & 4.1 & ND \\
\hline
\end{tabular}

$\mathrm{ND}=$ negative correlation focus not detected in control task in region specified; $Z$ values = normalized $t$ statistic values from the SPM-the larger the $Z$ value the greater the statistical association between decreasing $\mathrm{rCBF}$ and word list length, $Z=3.09=P<0.001$. 


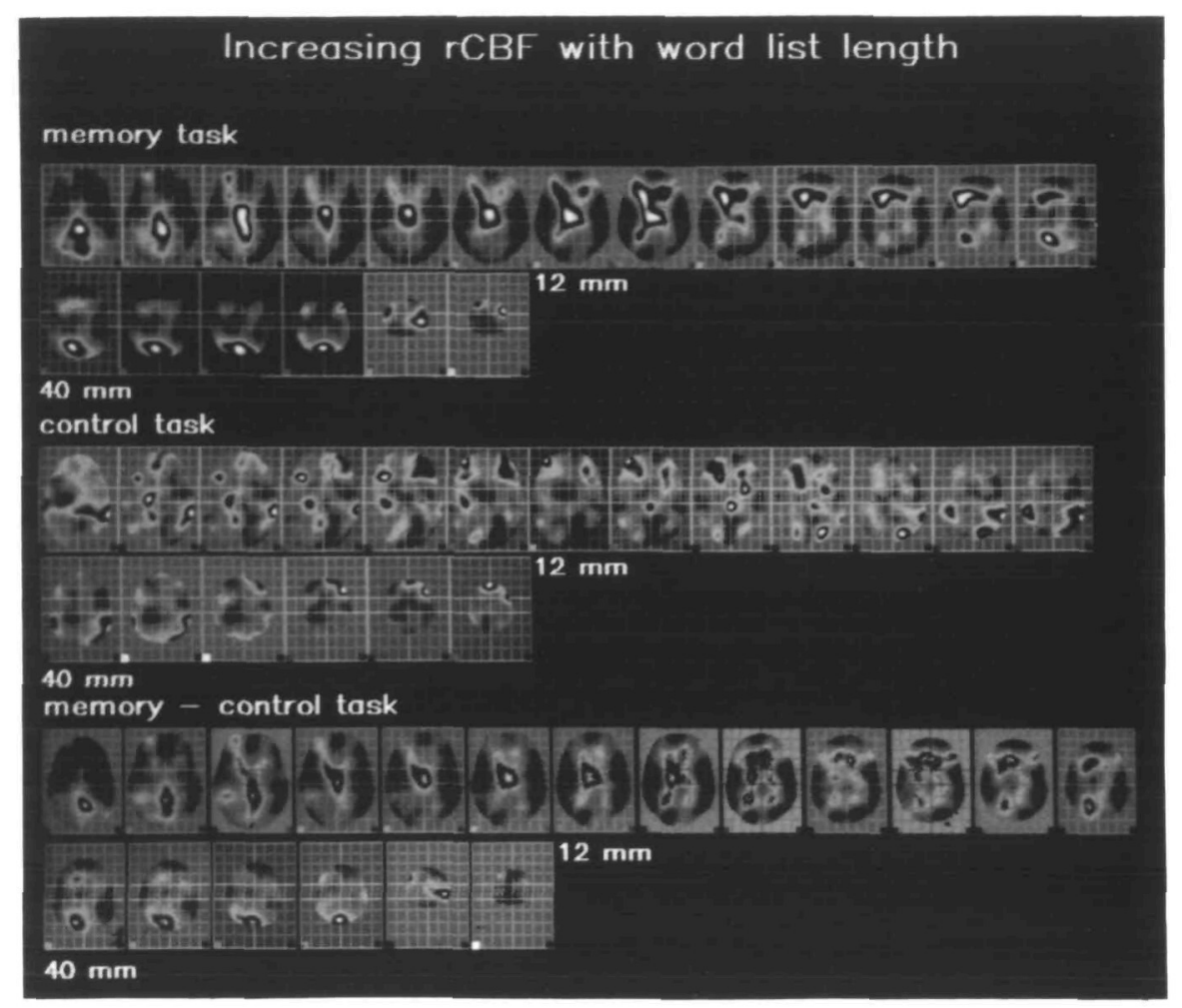

Fig. 3 Statistical parametric maps ( $t$ ) showing the location of significant correlations of rCBF with word list length for the control and memory task subjects. Images are transverse slices of the statistical volume relative to the AC-PC line. Numbers (e.g. $40 \mathrm{~mm}$ ) refer to the level of the transverse slice in millimetres relative to the AC-PC line. Anterior is at the top of each slice. The subjects right is on the right. The superimposed grid provides the stereotactic coordinates from the atlas of Talairach and Tournoux (1988). Upper two rows of images are SPMs showing correlations in the memory experiment, middle rows are correlations in the control task (word repetition), lower rows are significant correlations in the memory task minus those in the control task. The main similarity between the upper and middle sets of images are correlations in the prefrontal areas.

cerebellum, the thalamus, anterior cingulate, precuneus, prefrontal and superior temporal/insular cortical regions. Thus there is a high degree of similarity in the brain areas activated in the two studies. We based our previous memory activation experiment on the theoretical distinction between short- and long-term memory (Atkinson and Shriffin, 1968; Baddeley, $1976,1986)$ and used cognitive subtraction to isolate the neural correlates of a putative long-term auditory-verbal memory system (Grasby et al., 1993a). We argued that the essential difference between the subspan (five word list) and supraspan (15 word list) word list recall tasks was the degree to which long-term memory was active; the subtraction of the rCBF profile in the subspan task from the supraspan task being taken to isolate a $\mathrm{rCBF}$ profile that represented the engagement of long-term memory processes. This rCBF profile included the left and right dorsolateral prefrontal cortex, the retrosplenial area of the posterior cingulate and the precuneus. In addition, the comparison of the subspan and supraspan rCBF profiles with a rest state (in another group of subjects) identified a number of neural structures commonly activated in both the subspan and supraspan tasks including the cerebellum (vermis), thalamus and anterior cingulate. The design of the present experiment avoids some, but not all, of the theoretical assumptions implicit in both the previous cognitive subtraction paradigm and in the neuropsychological distinctions between short- and long-term memory systems. In this study we simply report the patterns of rCBF change in association with systematic manipulation of the experimentally defined variable of word list length.

\section{Memory performance and principal components analysis}

The spatial distribution of the first principal component was identical to the anatomically distributed system defined on the basis of brain areas responding to increasing word list length (Figs 1, 2 and 4). This suggests that most of the variance in this data set is explained by the experimental manipulation of word list length rather than some other unaccounted variable. A clear relationship exists between the first principal component and the averaged number of words 

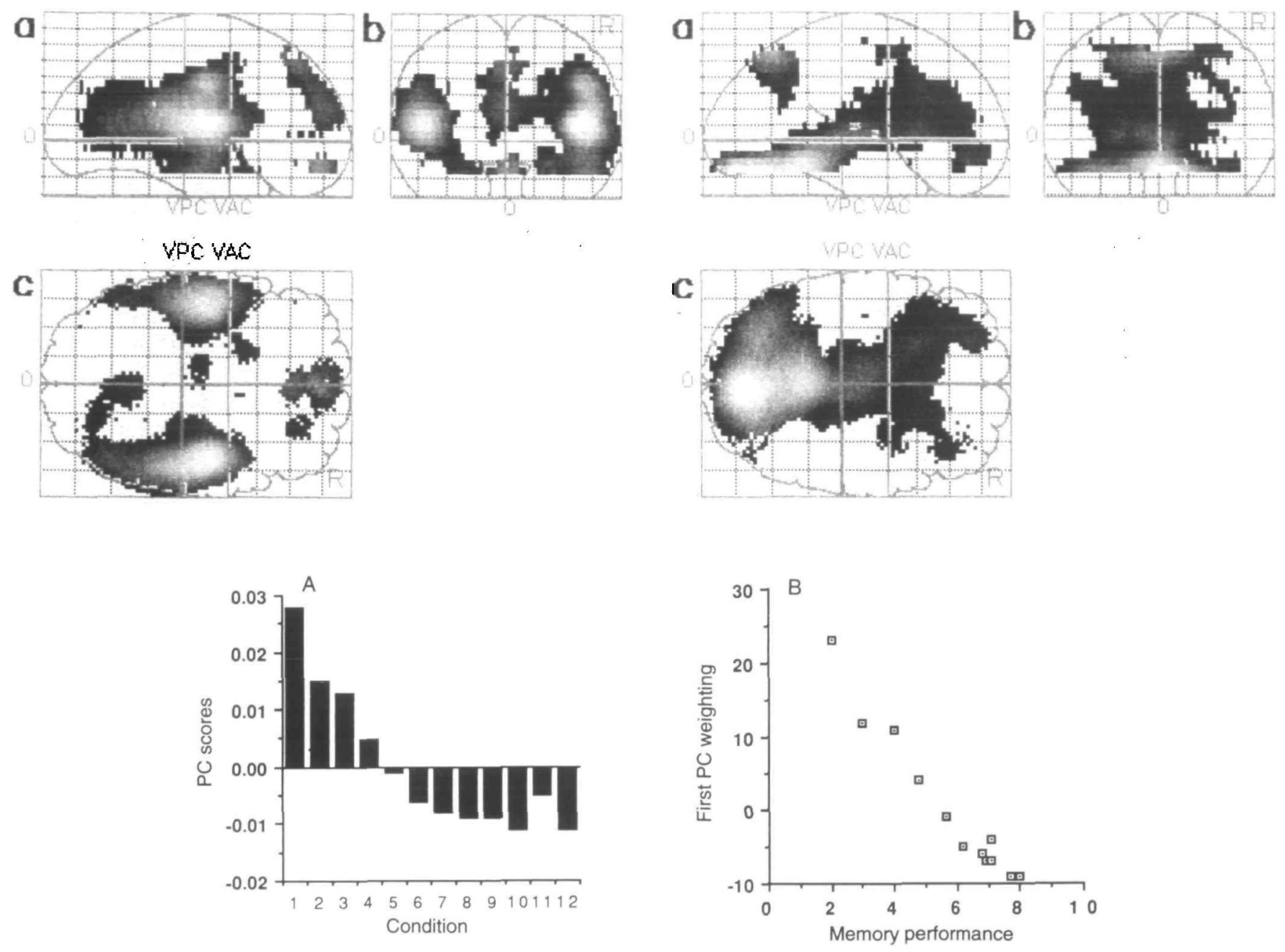

Fig. 4 Upper images: SPMs showing the spatial distribution of the first principal component or eigen-image where positive and negative parts are shown separately. Images are shown as integrated projections along sagittal (a), coronal (b) and transverse views (c) of the Talairach and Tournoux brain atlas. $\mathrm{R}=$ right. $\mathbf{A}$ shows the relative weighting of the first principal component (PC) across the 12 scans, ordered from a two word list (condition 1, left) to a 13 word list (condition 12, right). B shows the correlation of the weightings for the first principal component (PC) for scans of two to 13 word list length with subjects averaged memory performance for each word list (two word list, left to 13 word list, right).

recalled by subjects per scan, demonstrated by the high correlation of the loadings of the first principal component across scans with averaged memory performance per scan (Fig. 4). The manipulation of the independent variable (word list length) produced a clear change in $\mathrm{rCBF}$ and in memory performance. The high correlation of the first principal component with memory performance illustrates the degree to which rCBF (a physiological index of memory function in this study) and memory performance (a behavioural index of memory function) are coupled under the conditions of the experiment. The (high) weightings for the first principal component changed appreciably across the first five to six conditions (word list length two to seven) but thereafter were more or less equally weighted across conditions seven to 12 (word lists eight to 13) (Fig. 4). This suggests that the main experimental manipulations to affect $\mathrm{rCBF}$ were occurring in scans of two to seven word list length. This is also seen in the $\mathrm{rCBF}$ changes for some areas (e.g. left thalamus) which appeared to be increasingly activated with lists up to six or seven words in length but thereafter no further activations occurred (Fig. 5).

\section{Theoretical memory systems and the graded response memory task}

Although the graded response task is best regarded as akin to a physiological experiment in which a stimulus parameter is systematically manipulated, it is pertinent to consider to what extent these results can be understood in relation to theoretical models of memory function. The most established and robust models have distinguished between a memory system(s) of limited capacity and short duration (primary memory, short-term memory, working memory) from a large 

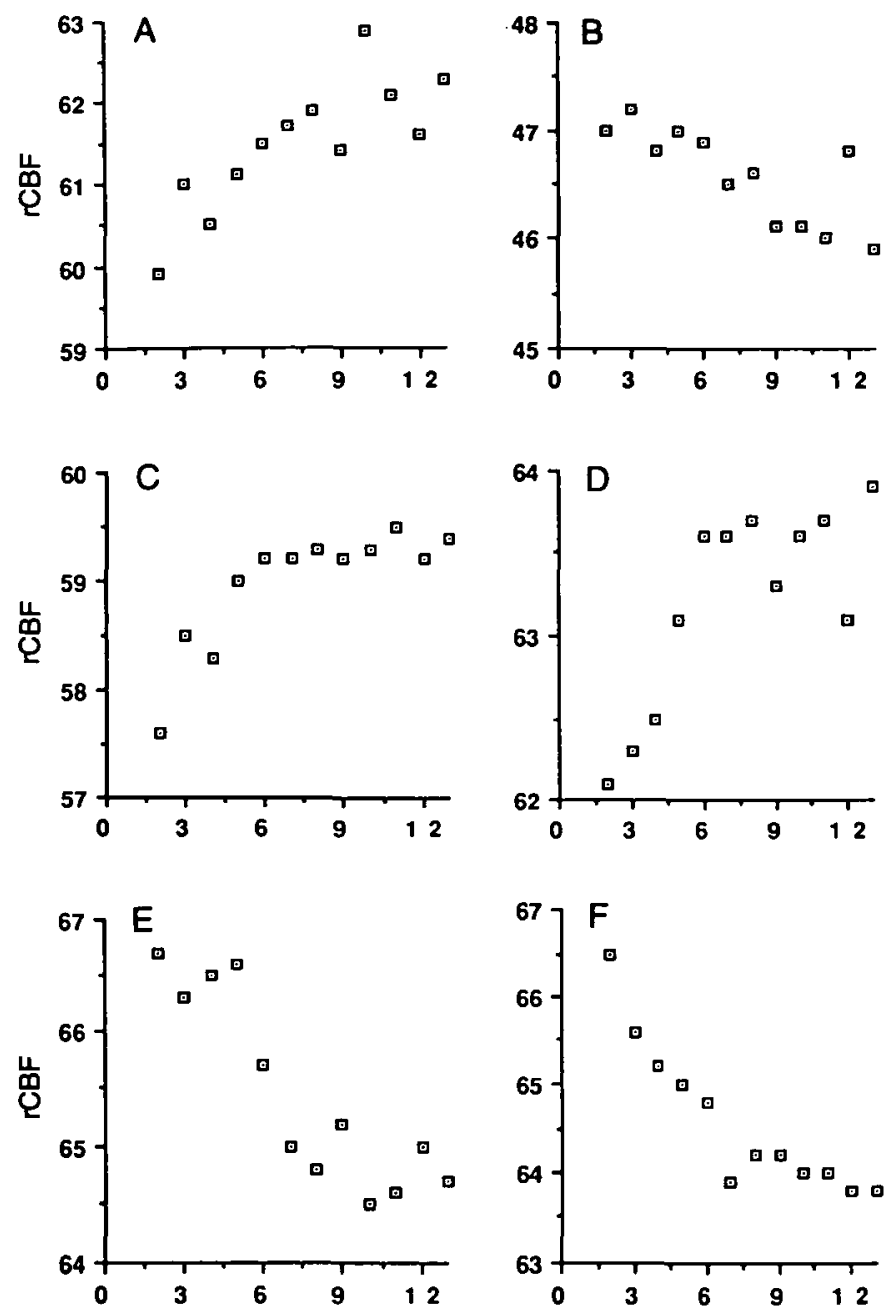

Fig. 5 Normalized rCBF data plotted against increasing word list length from foci of maximal correlation for $\mathbf{A}$ the precuneus $(-8,-60,44), \mathbf{B}$ medial frontal gyrus $(-4,54,20), \mathrm{C}$ left thalamus $(-2,-4,4)$, D right thalamus $(2,-28,4), \mathbf{E}$ left superior temporal/ insular cortex $(42,-12,8)$ and $\mathbf{F}$ right superior temporal/insular cortex $(42,-12,8)$ (data given in $x, y$ and $z$ coordinates, respectively).

capacity long-term system (secondary memory, long-term memory) (Atkinson and Shriffin, 1968; Baddeley and Warrington, 1970; Baddeley, 1976, 1986; McCarthy and Warrington, 1990). Evidence for an anatomical separation of shortand long-term memory systems is provided by the clinicoanatomical studies of amnesic patients such as H.M. (Scoville and Milner, 1957) and K.F. (Shallice and Warrington, 1970) in whom a double dissociation of long- and short-term memory systems is apparent. Neuropsychological findings would suggest that in this graded response task both of these theoretical memory systems may be operative. For example, in the free recall of supraspan word lists the recency effect is taken to represent the operation of a short-term memory system (Vallar and Papagano, 1986), whilst recall in other parts of the list is indicative of long-term memory function (Capitani et al., 1992). In contrast, when subjects are presented with a sequence of digits just beyond their span, and the same sequence is surreptitiously repeated every three presentations, the probability of recall of the repeated sequence increases over successive presentations suggesting engagement of long-term memory systems in a task that predominantly involves short-term memory (Melton, 1963). These two systems may operate in a reciprocal manner under certain conditions. Thus when an auditory signal is given to signify the approaching end of a supraspan word list, subjects' performance on the immediate recall of the last few items is improved (recency is enhanced); however, when delayed recall (long-term memory) of these items is tested at the end of the experiment the words are less well recalled compared with a control task of no auditory signal (Shallice, 1975). This suggests that if short-term memory processes are enhanced there is a concomitant reduction in long-term memory function. If both long- and short-term memory systems are activated in the graded response memory tasks, we would assume that long-term memory systems are increasingly activated as word list length is increased, whilst, in parallel, activation in short-term memory systems either remains constant or declines with increasing word list length. Therefore, it is possible that the increases of rCBF in select brain areas, with increasing word list length, correspond to increasing engagement of long-term memory processes. This view is supported by the fact that the areas identified as showing increased rCBF with word list length do not include the left temporoparietal region and inferior frontal gyrus which have been implicated in short-term memory function on the basis of lesion studies (Warrington et al., 1971; Shallice and Vallar, 1990) and a PET activation study (Paulesu et al., 1993). Indeed the brain areas described by Paulesu et al. (1993) as implicated in verbal short-term memory (left BA 44 and left BA 40) are within the large left-sided focus of decreasing rCBF with increasing word list length (Fig. 2).

The principal components analysis and $\mathrm{rCBF}$ responses in select individual brain regions (Figs 4 and 5) revealed that activity in many areas of the identified memory system did not increase appreciably for lists longer than seven words. On this basis we propose that the brain areas we have identified are primarily associated with a simple limited capacity system for encoding and retrieving material in memory.

The medial temporal region, particularly the hippocampal formation, has been equated with long-term memory function (Scoville and Milner, 1957; Drachman and Arbit, 1966; Squire and Zola-Morgan, 1991). No association between word list length and hippocampal/parahippocampal rCBF was observed when correlating across all word list lengths (two to 13 word lists). However, when rCBF correlations were performed for 'subspan' (two to seven word lists) and 'supraspan' (eight to 13 word lists) word list length separately (data not shown) we identified a focus of increasing rCBF with increasing supraspan word list length in the left hippocampal/ parahippocampal region (stereotactic coordinates $-10,-42$, 4 in $x, y$ and $z$ planes, respectively, $Z$ score $=3.7$ ). We have also identified and reported elsewhere (Grasby et al., 1993b) 
a similiar focus of increasing rCBF, in the region of the left hippocampus/parahippocampus when correlating rCBF with the number of words correctly recalled from the mid-portion of the serial position curve of word lists of length seven words and above. The mid-portion of the serial position curve was chosen as a relatively pure measure of long-term memory function (Capitani et al., 1992). In this study supraspan word list length and words correctly recalled from the mid-portion of the serial position curve were highly correlated and are putative measures of long-term memory load and performance, respectively. However, the pattern of activity reported in the hippocampal region is very different from other areas identified in this study where rCBF was correlated across all scans. This suggets that hippocampal areas may have a distinct role in the encoding/retrieval process that differs from regions such as the thalamus and precuneus.

\section{Decreases of $\mathrm{rCBF}$ in the region of the superior temporal/insular cortex with increasing word list length}

Clear decreases of $\mathrm{rCBF}$ were seen in the superior temporal/ insular region as word list length was increased (Figs 2 and 5). No such correlation was seen in the control task (data not shown). A similar finding was reported in our previous study of word list learning of five and 15 word lists where a relative decrease in this region was reported for the 15 word list compared with the five word list condition. Similar decreases in this area have been reported in a verbal fluency paradigm compared with the control task of word shadowing (Frith et $a l ., 1991 b$ ) and in the retrieval phase of an episodic memory task where subjects give learnt category exemplars (e.g. 'cheese' response 'gouda'). When this latter task was compared with a word repetition task (e.g. 'animal' response 'animal') reductions of $\mathrm{rCBF}$ were noted in the superior temporal/insular region (Shallice et al., 1994). In addition, when subjects are required to speak a verb on seeing a noun (e.g. 'cheese' response 'eat'), decreases of $\mathrm{rCBF}$ in the Sylvian insular cortex occur in comparison with simple noun repetition, unless the noun-verb associations have been practised (Raichle, 1991; Raichle et al., 1993). These data suggest that such decreases in temporal/insular cortex rCBF cannot be simply ascribed to a subtle confounding effect of variations in speech output or auditory input. Rather they suggest an active process of deactivation in this area with certain linguistic and memory tasks.

\section{Prefrontal correlations in both memory and control tasks}

When the rCBF profile of positive and negative correlations of word list length was compared with the control condition, the only areas that appeared to a be equally activated with both tasks were the prefrontal areas. Although prefrontal areas are implicated in memory function (Jetter et al., 1986;
Janowsky et al., 1989; Shimamura et al., 1991) prefrontal activations (particularly dorsolateral areas) have also been described in a number of PET studies variously characterized by intrinsic generation (Frith et al., 1991a), semantic processing (Petersen et al., 1988, 1989) or monitoring of self-generated or externally cued responses (Petrides $e t$ al., 1993). Furthermore, Fuster (1980) has emphasized the role that the frontal lobes play in the temporal organization of behaviour. In our memory tasks subjects have to switch from encoding processes to retrieval processes and, in the control task, from listening to speaking. Thus the prefrontal activations observed in this study may reflect the involvement of processes, other than memory, that are held in common with the control task, such as organizational/supervisory aspects of word list generation and/or speech production.

\section{Distributed neural systems}

A potentially useful framework for understanding the patterns of cerebral activations revealed in this and other imaging studies of memory function (Fazio et al., 1992; Perani et al., 1993 ) is that of distributed neural networks and parallel processing (Mesulam, 1990). Such distributed systems rely on direct or indirect anatomical connections between brain areas. Reciprocal anatomical connections between many of the areas of the network we have identified have been demonstrated in anatomical tract tracing studies (GoldmanRakic et al., 1984; Goldman-Rakic and Porrino, 1985; Goldman-Rakic, 1987, 1988). Although such a memory system might be distributed it does not necessarily imply that each brain area is equipotential in terms of the cognitive operations that constitute memory function. In this study we cannot distinguish between activity associated with the encoding and retrieval stages of memory since both occur during scanning. It is therefore possible that some areas we have identified are associated with encoding while others are concerned with retrieval. Preliminary evidence from a study in which these stages were examined separately (Shallice et al., 1994) suggests this is the case. Previous studies also suggest that certain areas have more specific roles. For example, the activation of the anterior cingulate cortex with increasing word list length may relate primarily to the attentional demands of the memory task as this structure is implicated in attentional mechanisms (Pardo et al., 1990; Bench et al., 1993). The exact functional roles of other areas in the identified network are not known. For instance, in our previous study and the graded response task reported here, the precuneus area (posterior parietal cortex, BA 7/31) showed clear and robust activation with increasingly word list length. Furthermore, Petrides et al. (1993) showed significant activations in this area in a task that involved verbal working memory. Despite these PET findings, the role of the precuneus in verbal memory function is unexplored to our knowledge.

The word list memory task is clearly dependent on linguistic function and speech production or auditory stimulation activates some but not all of the areas identified in this study. Thus repeating auditorily presented words is 
associated with increases of rCBF in Broca's area, the insular, sensorimotor cortex representing mouth and vocalization, the supplementary motor area and the paramedian cerebellum, whilst hearing words increases $\mathrm{rCBF}$ in the superior temporal cortex and anterior cingulate cortex (Petersen et al., 1988, 1989; Petrides et al., 1993). Thus, there is clearly some overlap between the areas activated by simple linguistic tasks and our graded response memory tasks although the overall pattern of activation is not that expected from simple auditory stimulation or speech output. Indeed the majority of brain areas identified in our graded memory experiment cannot be explained simply in terms of auditory input or speech output processes per se, as this was controlled for in the comparison with the control task. In this comparison the only brain areas that were equally activated by both tasks were the prefrontal areas (BA 10,46). The results of our study also have some similarities with more complex linguistic tasks. For example, intrinsic word generation (verbal fluency tasks) produce activations in the left dorsolateral prefrontal cortex, the left parahippocampal gyrus, Brodmann's area 39 and the anterior cingulate, and decreases of rCBF in the superior temporal cortex (Frith et al., 1991b). Such similarities suggest that auditory-verbal memory tasks necessarily recruit, at least in part, those brain areas that are involved in complex linguistic function. Within a framework of distributed neural systems, this implies that auditory-verbal memory function entails the simultaneous operation of overlapping networks that include those for attention, auditory input, speech production and linguistic analysis.

\section{Acknowledgements}

We wish to thank the staff of the MRC Cyclotron Unit who made this study possible. We also wish to thank Professor Tim Shallice and Dr Eraldo Paulesu for their helpful criticism in the preparation of this paper.

\section{References}

Atkinson RC, Shriffin RM. Human memory: a proposed system and its control processes. In: Spence KW, Spence JT, editors. The psychology of learning and motivation: advances in research and theory, Vol. 2. New York: Academic Press, 1968: 89-195.

Baddeley AD. The psychology of memory. New York: Basic Books, 1976.

Baddeley AD. Working memory. Oxford psychology series, No. 11. Oxford: Clarendon Press, 1986.

Baddeley AD, Warrington EK. Amnesia and the distinction between long- and short-term memory. J Verb Learn Verb Behav 1970; 9; 176-89.

Bailey DL, Jones T, Spinks TJ, Gilardi MC, Townsend DW. Noise equivalent count measurements in a neuroPET scanner with retractable septa. IEEE Trans Med Imag 1991a; 10: 256-60.

Bailey DL, Jones T, Friston KJ, Colebatch JG, Frackowiak RSJ. Physical validation of statistical parametric mapping [abstract]. J Cereb Blood Flow Metab 1991b; 11 Suppl 2: S150.
Bench CJ, Frith CD, Grasby PM, Friston KJ, Paulesu E, Frackowiak RSJ, et al. Investigations of the functional anatomy of attention using the Stroop test. Neuropsychologia 1993; 31: 907-22.

Capitani E, Della Sala S, Logie RH, Spinnler H. Recency, primacy, and memory: reappraising and standardising the serial position curve. Cortex 1992; 28: 315-42.

Damasio AR, Geschwind N. Anatomical localization in clinical neuropsychology. In: Vinken PJ, Bruyn GW, Klawans HL, editors. Handbook of clinical neurology, Vol. 45. Amsterdam: Elsevier, 1985: 7-22.

Drachman DA, Arbit JA. Memory and the hippocampal complex. Il. Is memory a multiple process? Arch Neurol 1966; 15: 52-61.

Fazio F, Perani D, Gilardi MC, Colombo F, Cappa SF, Vallar G, et al. Metabolic impairment in human amnesia: a PET study of memory networks. J Cereb Blood Flow Metab 1992; 12: 353-8.

Fox PT, Mintun MA. Non-invasive functional brain mapping by change distribution analysis of averaged PET images of $\mathrm{H}_{2}{ }^{15} \mathrm{O}$ tissue activity. J Nucl Med 1989; 30: 141-9.

Friston KJ, Passingham RE, Nutt JG, Heather JD, Sawle GV, Frackowiak RSJ. Localization in PET images: direct fitting of the intercommissural (AC-PC) line. J Cereb Blood Flow Metab 1989; 9: 690-5.

Friston KJ, Frith CD, Liddle PF, Dolan RJ, Lammertsma AA, Frackowiak RSJ. The relationship between global and local changes in PET scans. J Cereb Blood Flow Metab 1990; 10: 458-66.

Friston KJ, Frith CD, Liddle PF, Frackowiak RSJ. Plastic transformation of PET images. J Comput Assist Tomogr 1991 a; 15: 634-9.

Friston KJ, Frith $\mathrm{CD}$, Liddle PF, Frackowiak RSJ. Comparing functional (PET) images: the assessment of significant change. $J$ Cereb Blood Flow Metab 1991b; 11: 690-9.

Friston KJ, Frith CD, Liddle PF, Frackowiak RSJ. Functional connectivity: the principal component analysis of large (PET) data sets. J Cereb Blood Flow Metab 1993; 13: 5-14.

Frith CD, Friston KJ, Liddle PF, Frackowiak RSJ. Willed action and the prefrontal cortex in man: a study with PET. Proc R Soc Lond Biol 1991a; 244: 241-6.

Frith CD, Friston KJ, Liddle PF, Frackowiak RSJ. A PET study of word finding. Neuropsychologia 1991b; 29: 1137-48.

Fuster JM. The prefrontal cortex. New York: Raven Press, 1980.

Goldman-Rakic PS. Circuitry of primate prefrontal cortex and regulation of behavior by representational memory. In: Mountcastle VB, Plum F, editors. Handbook of physiology, Sect. 1, Vol. V, Pt. 1. Bethesda (MD): American Physiological Society, 1987: 373-417.

Goldman-Rakic PS. Topography of cognition: parallel distributed networks in primate association cortex. [Review]. Annu Rev Neurosci 1988; 11: 137-56.

Goldman-Rakic PS, Porrino LJ. The primate mediodorsal (MD) nucleus and its projection to the frontal lobe. J Comp Neurol 1985; 242: 535-60. 
Goldman-Rakic PS, Selemon LD, Schwartz ML. Dual pathways connecting the dorsolateral prefrontal cortex with the hippocampal formation and parahippocampal cortex in the rhesus monkey. Neuroscience $1984 ; 12: 719-43$.

Grasby PM, Frith CD, Friston KJ, Bench C, Frackowiak RSJ, Dolan RJ. Functional mapping of brain areas implicated in auditory-verbal memory function. Brain 1993a; 116: 1-20.

Grasby PM, Frith CD, Friston KJ, Frackowiak RSJ, Dolan RJ. Activation of the human hippocampal formation during auditoryverbal long-term memory function. Neurosci Lett 1993b; 163: 185-8.

Hand DJ, Taylor CC. Multivariate analysis of variance and repeated measures: a practical approach for behavioural scientists. London: Chapman and Hall, 1987: 9-44.

Janowsky JS, Shimamura AP, Kritchevsky M, Squire LR. Cognitive impairment following frontal lobe damage and its relevance to human amnesia. Behav Neurosci 1989; 103: 548-60.

Jetter W, Poser U, Freeman RB Jr, Markowitsch HJ. A verbal longterm memory deficit in frontal lobe damaged patients. Cortex 1986; 22: $229-42$.

Jonides J, Smith EE, Koeppe RA, Awh E, Minoshima S, Mintun MA. Spatial working memory in humans as revealed by PET [see comments]. Nature 1993; 363: 623-5. Comment in: Nature 1993; 363: $583-4$.

McCarthy RA, Warrington EK. Cognitive neuropsychology-a clinical introduction. San Diego: Academic Press, 1990: 275-95.

Mazziotta JC, Huang SC, Phelps ME, Carson RE, MacDonald NS, Mahoney K. A non-invasive positron computed tomography technique using oxygen-15-labeled water for the evaluation of neurobehavioral task batteries. J Cereb Blood Flow Metab 1985; 5: 70-8.

Melton AW. Implications of short term memory for a general theory of memory. J Verb Learn Verb Behav 1963; 2: 1-21.

Mesulam MM. Large scale neurocognitive networks and distributed processing for attention, language, and memory. [Review]. Ann Neurol 1990; 28: 597-613.

Pardo JV, Pardo PJ, Janer KW, Raichle ME. The anterior cingulate cortex mediates processing selection in the Stroop attentional conflict paradigm. Proc Natl Acad Sci USA 1990; 87: 256-9.

Paulesu E, Frith CD, Frackowiak RSJ. The neural correlates of the verbal component of working memory [see comments]. Nature 1993; 362: 342-5. Comment in: Nature 1993; 363: 583-4.

Perani D, Bressi S, Cappa SF, Vallar G, Alberoni M, Grassi F, et al. Evidence of multiple memory systems in the human brain. Brain 1993; 116: 903-19.

Petersen SE, Fox PT, Posner MI, Mintun M, Raichle ME. Positron emission tomographic studies of the cortical anatomy of singleword processing. Nature 1988; 331: 585-9.

Petersen SE, Fox PT, Posner MI, Mintun M, Raichle ME. Positron emission tomographic studies of the processing of single words. J Cogn Neurosci 1989; $1: 153-70$

Petrides M, Alivisatos B, Meyer E, Evans AC. Functional activation of the human frontal cortex during the performance of verbal working memory tasks. Proc Natl Acad Sci USA 1993; 90: 878-82.
Price C, Wise RJS, Ramsay S, Friston KJ, Howard D, Patterson K, et al. Regional response differences within the human auditory cortex when listening to words. Neurosci Lett 1992; 146: 179-82.

Quinlan PT. The Oxford psycholinguistic database. Oxford: Oxford University Press, 1992.

Raichle ME. Circulatory and metabolic correlates of brain function in normal humans. In: Mountcastle VB, Plum F, editors. Handbook of physiology, Sect. 1, Vol. V, Pt. 2. Bethesda (MD): American Physiological Society, 1987: 643-74.

Raichle ME. Memory mechanisms in the processing of words and word-like symbols. [Review]. Ciba Found Symp 1991; 163: 198-217.

Raichle ME, Fiez JA, Videen TO, Macleod AK, Pardo JV, Fox PT, Petersen SE. Practice-related changes in human brain functional anatomy during non-motor learning. Cereb Cortex 1994; 4: 8-26.

Robb RA. A software system for interactive and quantitative analysis of biomedical images. In: Höhne KH, Fuchs H, Pizer SM, editors. 3D imaging in medicine: algorithms, systems, applications. London: Springer-Verlag, 1990: 333-61.

Roland PE, Seitz RJ. Mapping of learning and memory functions in the human brain. In: Ottoson D, Rostène W, editors. Visualization of brain functions. Basingstoke: Macmillan Press, 1989: 141-51.

Scoville WB, Milner B. Loss of recent memory after bilateral hippocampal lesions. J Neurol Neurosurg Psychiatry 1957; 20: $11-21$.

Shallice T. On the contents of primary memory. In: Rabbitt PMA, Dornic S, editors. Attention and performance V. London: Academic Press, 1975: 269-80.

Shallice T, Vallar G. The impairment of auditory-verbal shortterm storage. In: Vallar G, Shallice T, editors. Neuropsychological impairments of short-term memory. Cambridge: Cambridge University Press, 1990: 11-53.

Shallice T, Warrington EK. Independent functioning of verbal memory stores: a neuropsychological study. Q J Exp Psychol 1970; 22: $261-73$.

Shallice T, Fletcher P, Frith CD, Grasby P, Frackowiak RSJ, Dolan RJ. The brain regions associated with the acquisition and retrieval of verbal episodic memory. Nature 1994; 368: 633-5.

Shimamura AP, Janowsky JS, Squire LR. What is the role of frontal lobe damage in memory disorders? In: Levin HS, Eisenberg HM, Benton AL, editors. Frontal lobe function and dysfunction. New York: Oxford University Press, 1991: 173-95.

Squire LR, Zola-Morgan S. The medial temporal lobe memory system. [Review]. Science 1991; 253: 1380-6.

Squire LR, Ojemann JG, Miezin FM, Petersen SE, Videen TO, Raichle ME. Activation of the hippocampus in normal humans: a functional anatomical study of memory. Proc Natl Acad Sci USA 1992; 89: 1837-41.

Sternberg S. The discovery of processing stages: extensions of Donders' method. In: Koster WG, editor. Attention and performance II. Acta Psychologica Vol. 30. Amsterdam: North-Holland, 1969: 276-315. 
Talairach J, Tournoux P. Co-planar stereotaxic atlas of the human brain: 3-dimensional proportional system: an approach to cerebral imaging. Stuttgart: G. Thieme, 1988.

Townsend DW, Geissbuhler A, Defrise M, Hoffman EJ, Spinks TJ, Bailey DL, et al. Fully three-dimensional reconstruction for a PET camera with retractable septa. IEEE Trans Med Imag 1991; 10: 505-12.

Vallar G, Papagano C. Phonological short-term store and the nature of the recency effect: evidence from neuropsychology. Brain Cogn 1986; $5: 428-42$.

Warrington EK, Logue V, Pratt RTC. The anatomical localisation of selective impairment of auditory-verbal short-term memory. Neuropsychologia 1971; 9: 377-87.

Wildt AR, Ahtola OT. Analysis of covariance. Quantitative applications in the social sciences, Vol. 12. Beverly Hills: Sage, 1978.

Woods RP, Cherry SR, Mazziotta JC. Rapid automated algorithm for aligning and reslicing PET images. J Comput Assist Tomogr 1992; 16: 620-33.

Received March 31, 1994. Revised June 20, 1994.

Accepted June 24, 1994 